\title{
La Agenda Global de las Naciones Unidas para "la Mujer"*
}

\section{Doris Lamus Canavate**}

Resumen: El presente artículo muestra el proceso mediante el cual, a partir de un conjunto de instituciones, convenciones, conceptos, métodos, categorías, normas y prácticas discursivas, se define no sólo un campo en disputa, sino toda una agenda que construye y reconstruye a lo largo de varias décadas un proyecto cultural y político de transformación de culturas patriarcales dominantes en los otrora llamados países del Tercer Mundo.

Palabras clave: discurso, feminismo, movimientos sociales, patriarcado, género

\section{The Global Agenda of United Nations for "Women"}

Abstract: This paper shows the process through which, starting with a group of institutions, conventions, concepts, methods, categories, rules, and discursive practices, not only an area in dispute is defined, but an entire agenda which builds and rebuilds through decades, a political and cultural project that transforms the dominant patriarchal cultures in the former so-called Third World countries.

Key words: speech, feminism, social movements, patriarchy, gender

Recibido: 21.05.08 Aceptado: 21.07 .08

Quisiera mostrar, con ejemplos precisos, que analizando los propios discursos se ve cómo se afloja el lazo, al parecer tan fuerte, de las palabras y de las cosas, y se desprende un conjunto de reglas adecuadas a la práctica discursiva. Estas reglas definen no la existencia muda de una realidad, no el uso canónico de un vocabulario sino el régimen de los objetos. (...) Tarea que consiste en no tratar-

en dejar de tratar- los discursos como conjuntos de signos (de elementos significantes que envían a contenidos o a representaciones), sino como prácticas que forman sistemáticamente los objetos de que hablan.

(Foucault, 1984:80-81)

\footnotetext{
* Este artículo forma parte de un trabajo de tesis doctoral titulado "De la subversión a la inclusión: movimiento(s) de mujeres de la segunda ola en Colombia”, realizado en la Universidad Andina Simón Bolívar, en el Programa de Doctorado en Estudios Culturales, entre 2002 y 2007.

*** Universidad Autónoma de Bucaramanga, Bucaramanga, Colombia. Email: dlamus@unab.edu.co
} 


\section{Introducción}

Los discursos y las prácticas feministas de la segunda ola en Colombia y en los demás países de la región, tiene sus orígenes de los decenios de los años 60/70, en el contexto de las transformaciones culturales protagonizadas por nuevas generaciones de mujeres y hombres que cuestionaban la moralidad dominante. En el caso de las mujeres, las primeras demandas de esta nueva etapa del feminismo estuvieron orientadas a hacer visible, público y político, todo aquello que había permanecido reducido a la vida privada, a la intimidad, asunto que emerge como la convicción fundamental del nuevo feminismo: lo personal es político. Así mismo, en este contexto, demandas tales como el aborto libre y gratuito y la crítica contra la Iglesia, van a ser el leit motiv de la movilización femenina.

Pero este campo de formación discursiva que identificaré como el de la segunda ola del feminismo va a tener en su construcción, varias lógicas que responden a las relaciones de poder que en tal proceso se juegan: Las que construyen local/regional/nacionalmente las mujeres en sus particulares contextos políticos y culturales, y las que se forman a partir de dinámicas e intereses globales, desde los centros de poder, como Naciones Unidas y las agencias de cooperación internacional.

Lo que a continuación desarrollo como institucionalización del discurso sobre "la mujer", es precisamente el proceso o mecanismo por medio del cual las demandas de las mujeres van siendo incorporadas en una institucionalidad que define el campo discursivo y las reglas de juego del mismo, en el que progresivamente van entrando con mayores o menores resistencias, las organizaciones, sus discursos y sus prácticas, participando activamente en la construcción y ampliación de esa agenda conforme a sus intereses, pero dentro del campo de juego establecido.

El ejercicio está inspirado en el trabajo de Arturo Escobar, La Invención del Tercer Mundo (2000), en el cual el autor sostiene que los modelos universales, como el del desarrollo, reproducen formas del discurso que contribuyen al ejercicio de la dominación social y cultural, al tiempo que niegan/ocultan la capacidad de la gente para moldear su propio comportamiento. El supuesto básico del que parte en sus trabajos es que las tradiciones en la antropología (también en la economía y la política) han disuelto en sus discursos, las prácticas culturales cotidianas (locales) como terreno y fuente de prácticas políticas.

Tratando, pues, de desentrañar la lógica global que emerge en el caso de las movilizaciones de las mujeres/feministas en Latinoamérica, abordo estos procesos en una aproximación global, desde la agenda internacional, que reconstruye el proceso de formación del discurso y las prácticas feminista en la región.

En un principio, las estrategias de Naciones Unidas para el desarrollo del Tercer Mundo -de las que se ocupa Escobar-, focalizaron sus acciones en las mujeres con la 
perspectiva de que toda inversión en ellas representa mayores "tasas de retorno". Por ello la lucha contra la pobreza y el atraso tiene un fuerte énfasis en la mujer-madre y en la vida doméstica, especialmente de áreas rurales. De esta manera, la intervención de los organismos e instituciones del desarrollo en favor de las mujeres ha marcado las agendas tanto de las organizaciones femeninas/feministas, como la de los Estados y ha favorecido, más recientemente, la participación y la discusión de propuestas de la sociedad civil incluidas las organizaciones de mujeres-, los organismos no gubernamentales y de los Estados. ${ }^{1}$

El desarrollo como espacio de análisis del discurso en la perspectiva de Escobar, está planteado en el contexto de las continuidades y discontinuidades halladas por él a partir de los años 40 y 50 en este campo. En retrospectiva, si bien el objetivo del desarrollo, es decir, la lucha contra la pobreza en el Tercer Mundo ha fracasado, el objetivo de administrar y controlar mediante la incorporación gradual a la "modernidad occidental" de las poblaciones, ha sido exitoso y para ello se cuenta con un eficiente aparato burocrático, técnico y científico cada vez más especializado que sigue funcionando actualmente. La ciencia y la tecnología contribuyen a actualizar y difundir los ideales de progreso del proyecto moderno, ahora redefinido como desarrollo. ${ }^{2}$

De este modo, el proceso de institucionalización y profesionalización del desarrollo tiene en la especialización, ${ }^{3}$ un componente decisivo que permite seguir las huellas de un aspecto particular del mismo. En este caso, el discurso que construye a "la mujer" -en abstracto, como categoría representativa de la totalidad-, en objeto, se incorpora a las políticas del conocimiento especializado, mediante un conjunto de técnicas, estrategias y prácticas disciplinarias, que organizan, sistematizan y controlan la generación, validación, difusión del mismo, contando para ello con el aparato creado a mediados del siglo XX.

La referencia a estructuras o aparatos en este contexto no debe confundirse con la idea de un "algo" suprahumano (el poder) que maneja todo maquiavélicamente, o peor aún, con la idea de una "gran conspiración" oculta en todas partes; por el contrario, lo que señalo es que esta trama de instituciones, organismos, convenciones, acuerdos, leyes; teorías, conceptos y categorías; métodos, estrategias y técnicas, no existen

\footnotetext{
${ }^{1}$ Ver, Valdés 2000:83, Escobar 2000:324, 337, 340, León 1996:187-218; 1993; 1993A.

${ }^{2}$ Igual que el progreso, el desarrollo es concebido como un proceso acumulativo y creciente, además ordenado y estable, que va de una situación de carencia y precariedad a otra de mejoramiento general de las condiciones de existencia, generalmente medidas con indicadores cuantitativos. Esta concepción fue teorizada por W. W. Rostow, en Las etapas del crecimiento económico, que además subtituló Un manifiesto no comunista, publicado en 1960, por la Universidad de Cambridge

${ }^{3}$ Además de las luchas anticoloniales en Asia y África y el creciente nacionalismo latinoamericano, la guerra fría y el anticomunismo, la necesidad de nuevos mercados, otros factores que dieron forma al discurso del desarrollo fueron la superpoblación y la fe en la ciencia y la tecnología. (Escobar, 2000: 71). Destaco estos dos elementos por su pertinencia para el caso que nos ocupa.
} 
independientemente de unas agendas y unos actores sociales que las ponen en marcha; agendas y actores con intereses, relaciones de poder, concepciones de mundo y de futuro, al tiempo que con valoraciones sobre las culturas, las prácticas y las formas de vida de los/las otros/as. Todas ellas son creación humana. Tampoco el "aparato" funciona en una sola dirección, cada cual juega sus fichas estratégicamente en el campo definido, no necesariamente son agentes pasivos de las intervenciones. ¿Pero, quien define las reglas de juego y el campo mismo?

Lo que aquí importa subrayar es que no es posible pensar en fuerzas abstractas actuando al margen e independientemente de unos Estados, de unas instituciones, de unos organismos -financieros, entre otros- y de un "aparato" que funciona conforme a procesos que conciben, planean, diseñan, deciden y ejecutan, personas con toda su carga de valores e intereses individuales y colectivos.

\section{La institucionalización del discurso}

Terminada la segunda guerra mundial Estados Unidos promueve y obtiene la aprobación de una ley de cooperación económica para la reconstrucción europea, más conocida como Plan Marshall; con anterioridad, en 1945, las Naciones Unidas habían creado el Banco Internacional de Reconstrucción y Fomento, hoy Banco Mundial, y el Fondo Monetario Internacional.

Estos organismos financieros internacionales tenían, además de la finalidad de fortalecer el poder económico de los Estados Unidos, el objetivo político y estratégico de concentrar mayor poder en el contexto de la guerra fría. Una vez superada la crisis de la reconstrucción económica de la posguerra estos mismos organismos se orientaron hacia un propósito central: desarrollar, sacar de la pobreza y el atraso a los países del Tercer Mundo, especialmente los de América Latina.

El sistema institucional global está sostenido por dos pilares básicos: uno, el aludido, de carácter económico, centrado en el discurso del desarrollo (Escobar 2000), hoy enmarcado en el ideario neoliberal, el cual dispone de una eficiente red de organismos internacionales de cooperación y las agencias para el desarrollo (además de otros especializados) que le otorgan legitimidad, el tiempo que con el concurso -consciente o node muchos agentes locales, incorpora progresivamente todo discurso alternativo (indígenas, mujeres, ecologistas...) y en cada caso los conceptos, las estrategias, los proyectos, las propuestas que de este modo pierden todo carácter contestatario, crítico o antisistémico, para volverse técnico, supuestamente neutro, o "despolitizado".

El segundo pilar del sistema lo constituye el discurso sobre derechos humanos. Si bien ambos discursos juegan un papel fundamental en la institucionalización del discurso 
sobre "la mujer", el primero da lugar muy tempranamente a una visión econométrica y objetivista del desarrollo que no entiende la participación de la mujer más allá de su rol tradicional en la familia, con toda la carga de sobreexplotación que ello implica. Aunque progresivamente esta óptica va a modificarse por efecto de la producción teórica y la investigación feminista -como también la idea de "la mujer"-, el campo del desarrollo tiene una lógica centrada en el crecimiento y el capital que obstaculiza las expectativas de igualdad entre mujeres y hombres, en tanto que la veta sobre los derechos humanos va a construir el campo discursivo sobre "la mujer" desde una óptica más liberal. No niego, sin embargo, la importancia de las batallas por el control de las significaciones y el sentido del ser mujer que se juegan en ambos campos.

El discurso sobre la protección de los derechos humanos ingresa al lenguaje internacional en la segunda posguerra bajo la consideración de la necesidad de establecer un conjunto de principios comunes orientados a proveer medidas de protección de los derechos de las personas en todo el mundo, luego de los devastadores efectos de la guerra (Plata y Yanuzova 1988:31). Estos principios se encuentran originalmente en la legislación interna de algunos países, como la Carta Magna de Inglaterra, el Bill of Rights de la Constitución de los Estados Unidos y la Declaración de los Derechos del Hombre, en Francia (Walsh, 2003: $17 \mathrm{ss}$ ). ${ }^{4}$

De esta manera, la legislación sobre los derechos humanos comienza con la creación de la Organización de las Naciones Unidas y los organismos de su sistema en 1946, cuya Carta expresa en el preámbulo la voluntad de los pueblos de "reafirmar la fe en los derechos humanos fundamentales del hombre (sic), en la dignidad y el valor de la persona humana, y en la igualdad de derechos de hombres y mujeres". Así mismo, el artículo $1^{\circ}$ se propone "reafirmar la cooperación internacional en la solución de problemas internacionales de carácter económico, social, cultural y humanitario, y en el desarrollo y estímulo del respeto de los derechos humanos y a las libertades fundamentales a todos, sin hacer distinción por motivos de raza, sexo, idioma o religión". 5

En Naciones Unidas existe desde su creación en 1946, la Comisión de Igualdad Jurídica y Social de la Mujer, ${ }^{6}$ creada como comisión asesora del Consejo Económico y Social, responsable a su vez del programa de derechos humanos del sistema. En lo sucesivo

\footnotetext{
${ }^{4}$ Es decir, son locales, no universales: La visión del conocimiento geopolíticamente localizado, propuesta por Walter Mignolo quiere establecer un quiebre epistémico con el paradigma de la modernidad, que permita hacer visibles las historias ocultas o silenciadas por éste. La tesis central sostiene que el conocimiento (su creación, producción, distribución...) no es abstracto y deslocalizado: la historia del conocimiento está marcada geo-históricamente y además tiene un valor y un lugar de origen. En consecuencia, toda historia es siempre local: "la historia universal es universal en el enunciado pero local en la enunciación", (Entrevista a Walter Mignolo). Ver Mignolo (2003)..

${ }^{5}$ Carta de Naciones Unidas, www.un.org/spanish/abautun/charter.htm.

6 (Roig, 1985: 6-7) (Guzmán y Pacheco 1996: 21) (Plata y Yanuzova, 1988: 20). 
Naciones Unidas se ocupará en diversas convenciones, de los derechos de las mujeres en distintas esferas de actuación (Plata y Yanuzova 1988:9). ${ }^{7}$ La comisión ha sido la encargada de la redacción de las convenciones y declaraciones relativas a los derechos de las mujeres.

"En 1967 la Asamblea General de la ONU adoptó la Declaración sobre la Eliminación de la Discriminación contra la Mujer" (Plata y Yanuzova 1988:9). Precedida por varias convenciones, ${ }^{8}$ cada una con un tema particular sobre discriminaciones de que es objeto la mujer, esta Declaración "recoge los progresos y describe los medios necesarios para promover la igualdad de los derechos de hombres y mujeres" (ídem), para abolir las leyes, costumbres y prácticas basadas en la idea de la inferioridad de la mujer (Roig, 1985: $6)$.

Sin embargo, casi una década después (1976) la situación parece no modificarse y la agitación feminista se hace pública y creciente, ante la evidencia de que entre más se difunden los discursos democráticos, más notorias son las exclusiones de que son objeto la mitad de la población mundial. A partir de la década de los años 70, Naciones Unidas lidera la iniciativa en la construcción de una agenda internacional para la mujer en el mundo, para lo cual diseña e implementa planes y estrategias para avanzar en la igualdad de derechos y oportunidades, con la participación creciente de las organizaciones de mujeres, los Estados y la cooperación internacional, a lo largo del final de siglo.

"Es así como Naciones Unidas, en un acto que fue criticado en su momento por muchos grupos feministas como inútil, en 1975, declara éste como el "Año Internacional de la Mujer". Simultáneamente se realizan Conferencias mundiales, la primera de las cuales se realiza en México, este mismo año; en esta I Conferencia Mundial sobre la Mujer, es proclamado por la Asamblea General el Decenio de las Naciones Unidas para la Mujer: Igualdad, Desarrollo y Paz, de 1976-1985".

En estas Conferencias, Naciones Unidas convoca a todos los Estados miembros, a sus agencias especializadas y a otras instituciones del sistema, así como a organizaciones internacionales relacionadas con el tema, generalmente con el propósito de tratar asuntos de interés para todos los miembros y trazar políticas para ser ejecutadas por los países firmantes de los acuerdos establecidos. Las ONG con estatus consultivo participan como

\footnotetext{
${ }^{7}$ Derechos políticos (1948), trata de personas y prostitución (1949), igualdad en la remuneración (1951), nacionalidad de la mujer casada (1957), discriminación en el empleo y la profesión (1958), discriminación en la enseñanza (1960).

${ }^{8}$ En 1965 la Asamblea General de la ONU aprobó la Convención internacional para la eliminación de toda forma de discriminación racial, la cual formaba parte de la ética descolonizadora de la ONU en los años 60. Esta Convención dio lugar a la reflexión sobre la discriminación de las mujeres en razón de su sexo. En esta como en otras ocasiones, las luchas de las mujeres, ligadas a las de los hombres, a la vez que conquistaban las de los hombres, aplazaban las de las mujeres.

${ }^{9}$ Ver www.isis.cl/temas/conf/beijing.htm 
observadores. También participan ONG que no son consultivas, como observadoras (Guzmán y Pacheco 1996:18).

En consecuencia, en una conferencia participan actores diversos, con intereses también diversos y en ocasiones contrapuestos, lo cual plantea problemas conceptuales, metodológicos, epistemológicos y políticos; es decir, aquí se expresa la lucha por el control de los significados y atribuciones de sentido entre los diversos actores y sus formaciones discursivas. Las líneas que toma la política y en general la agenda, permiten identificar cuál es el discurso que va haciéndose hegemónico en esa lucha.

Así las cosas, la tarea iniciada con la Declaración sobre la eliminación de la discriminación contra la mujer continúa. La Comisión de la Condición Jurídica y Social de la Mujer produce entonces la Convención sobre la eliminación de todas las formas de discriminación contra la mujer. ${ }^{10}$ La Asamblea General de Naciones Unidas finalmente la aprueba el 18 de diciembre de 1979, en Nairobi. Y para septiembre de 2004, cerca de 174 países habían ratificado la Convención. En el caso de Colombia, es ratificada mediante la Ley 51 de 1981 y reglamentada mediante Decreto 1398 de 1990 (Plata y Yanuzova 1988).

El máximo logro del Decenio de las Naciones Unidas para la Mujer ha sido, a juicio de muchas feministas, la inclusión de la Convención en la legislación internacional de los derechos humanos. Conocida también por la sigla en inglés, CEDAW, la Convención es el documento más importante en términos de la construcción de un discurso que denuncia las raíces de la subordinación femenina fundada no sólo en las condiciones materiales sino culturales y simbólicas de la dominación patriarcal.

La Convención propone comprometer a todos los Estados en la tarea de "prevenir, sancionar y eliminar la discriminación contra las mujeres en todas sus formas", al tiempo que se concibe como instrumento para propiciar las medidas que procuren modificar tradiciones y prácticas naturalizadas de la discriminación, explotación y exclusión sociocultural, política, económica, en la educación, el trabajo, la vida civil, en la vida familiar, en el medio rural, con el fin de asegurar el pleno desarrollo y adelanto de la mujer, con el objeto de garantizarle el ejercicio y el goce de los derechos humanos y las libertades fundamentales en igualdad de condiciones con los hombres. El núcleo duro de la Convención lo constituye el art. 5, que en su literal a), señala:

Los Estados partes tomarán todas las medidas apropiadas para:

"Modificar los patrones socioculturales de conducta de hombres y mujeres, con miras a alcanzar la eliminación de los prejuicios y las prácticas consuetudinarias y de cualquier

${ }^{10}{ }^{10}$ En adelante indistintamente la Convención o CEDAW 
otra índole que están basados en la idea de la inferioridad o superioridad de cualquiera de los sexos o en funciones estereotipadas de hombres y mujeres" (Plata y Yanuzova 1988).

En este artículo está contenido el reconocimiento del carácter cultural e históricamente construido de las condiciones de subordinación de la mujer que en las relaciones sociales aparecen como "naturales". Sin entrar a discutir si estas prácticas culturales consuetudinarias y naturalizadas a través de la socialización, puedan cambiarse por medio de una Convención como ésta, quiero sostener que el hecho de poner en circulación un discurso legitimado por los organismos del sistema de Naciones Unidas y con el compromiso y la ratificación de los gobiernos, se abre una etapa de puesta en cuestión y de reconstrucción de imaginarios acerca de la mujer y su lugar en la sociedad, hecho que apunta justamente hacia el centro neurálgico de la dominación patriarcal. La CEDAW se constituye así en la versión contemporánea de la "Carta Magna de las Mujeres". ${ }^{11}$

Lo que quiero subrayar aquí es que ciertas decisiones como la de la declaración del Año Internacional y la Década de la Mujer, dan inicio a una etapa de institucionalización de un discurso sobre las mujeres que incorpora progresivamente las demandas de igualdad y no discriminación -no de emancipación- que las mujeres venían agitando desde los 60 y que se hacen más visibles en los 70, sin embargo de manera aislada y dispersa.

La institucionalización va a implicar organización creciente, regulación, formalización, la burocratización, especialización del discurso, y por tanto, la existencia de un conjunto de estructuras, instancias, a nivel global, nacional y local que definirá las reglas de juego dentro de las cuales las demandas de las mujeres circularán. Si bien este proceso va a permitir la internacionalización del movimiento y la intensificación de las relaciones entre las mujeres en el mundo, la institucionalización va a alentar nuevos y antiguos desequilibrios en las relaciones de poder entre las mujeres organizadas y profesionalizadas (Álvarez 2001:380).

Así mismo, la institucionalización va a implicar la incorporación del discurso sobre las mujeres en la agenda de los Estados para la formulación de políticas, que si bien habían venido incluyendo progresivamente en su legislación avances en la condición jurídica y social de las mujeres (Velásquez 1998:51-78), mantenían una visión de éstas ligada a sus roles tradicionales; así, la protección de la maternidad va a estar presente al tiempo con las demandas por el derecho al trabajo y a la educación. Esta visión se mantiene con posterioridad cuando se crean por vez primera instancias de gobierno, programas y oficinas

\footnotetext{
${ }^{11}$ Quiero insistir en que la CEDAW queda lista para ratificación y firma de los países en diciembre de 1979, por tanto el proceso de cabildeo para obtener su ratificación inicia en 1980. Colombia ratifica en 1981 y reglamenta en 1990.
} 
que responden a las necesidades de ciertas poblaciones, en este caso de las mujeres, pero en relación con la familia (Valdés :2000:98-99).

Esta operación de institucionalización del discurso (a través de estrategias como las de Mujer y Desarrollo (MYD), o Género y Desarrollo (GYD), o planeación con perspectiva de género), ligada a los Estados, y mediada por el conocimiento que sobre las mujeres se produce, incluso por las mujeres de la región (Gargallo 2004:19-21) ${ }^{12}$-académicas, investigadoras, expertas en $\mathrm{ONG}_{-}$, sirve de base parcial para la construcción de otras realidades institucionales que refuerzan, desarrollan, articulan, incorporan, pero también resignifican, la conceptualización de problemas como el "empoderamiento", o la ciudadanía, o la democracia, ya ensamblados en otras latitudes. No es, sin embargo, despreciable, el efecto de poder colonizador que se opera en la producción/circulación de estos discursos, proceso en el cual las mujeres podemos jugar un papel de mediadoras, muy poco críticas en algunos casos.

Sea este el momento para incluir una reflexión sobre las investigadoras feministas, de Muller, (1986:36-38) quien anota que cuando aceptamos sin cuestionamiento visiones de nuestros problemas a través del uso de categorías elaboradas en otros contextos, asumimos con ellas el régimen de representación de la organización social en la cual se construyen, por ejemplo, la concepción de sociedad, el ideal de desarrollo, de democracia, de mujer, entre muchos.

"El uso de procedimientos y estadísticas estandarizados hace inevitable cierta desaparición de la experiencia de la mujer. Las descripciones representativas se convierten en una manera de conocer y una manera de no conocer, una manera de hablar acerca de las mujeres y una manera de silenciarlas para que no hablen sobre su propia vida al tiempo que quedan organizadas por fuerzas externas, invisibles e incontrolables" (Muller, 1986:36-38).

Señala además que el aparato del desarrollo es el más grande, el más patriarcal y más dominante del mundo. Sin embargo aclara que no está condenando al feminismo como imperialista en sí mismo, sino reconociendo el poder de las fuerzas dominantes para apropiarse de nuestros tópicos, nuestro lenguaje, nuestra acción para propósitos imperialistas que nunca pueden ser iguales a los nuestros (Muller 1986). ${ }^{13}$

De esta manera, la historia y la cultura de estas sociedades, en relación con la vida de las mujeres, son "descubiertas"-como dice Escobar-, es decir, conocidas y traducidas en publicaciones del Norte y reenvasadas o reconceptualizadas como programas y proyectos

\footnotetext{
${ }^{12}$ Francesca Gargallo, sostiene que las agencias de cooperación no habrían podido imponer estas categorías de no ser porque algunas de las feministas ya se estaban encargando de difundir este conocimiento y menciona a varias de ellas, de Costa Rica, México y Argentina.

${ }^{13}$ Citada por Escobar, (2000: 339-340).
} 
que nos llegan a través de las expertas, las investigadoras, las académicas, las técnicas que asumen el papel de "agentes" de la colonización y el disciplinamiento (Escobar 2000:342).

No obstante la importancia de esta lectura crítica, habría que pensar que las mujeres de estas latitudes no son agentes pasivos de esa colonización, que los procesos de interacción con los organismos internacionales no ocurren en una sola dirección; por el contrario, son muy complejos y desde dentro del movimiento y sus redes se trabajan estratégicamente por la modificación de las condiciones de subordinación que la cultura ha impuesto a las mujeres; es decir, con una relativa conciencia de las implicaciones y relaciones de poder que en este ámbito se juegan, pero "aprovechando" las oportunidades que las circunstancias permiten.

Aunque buena parte del proceso de institucionalización del discurso del desarrollo (sustentado en la economía neoclásica) sobre la mujer mantiene una imagen de ella ligada a su condición de madre, la adopción de la CEDAW introduce un componente fundamental y profundo en la configuración social, cultural y simbólica de las mujeres en las sociedades latinoamericanas de la época: la posición de que la mujer como inferior y subordinada a los hombres que la cultura patriarcal naturaliza, es producto histórico, culturalmente construido a través de los siglos $\mathbf{y}$, por tanto, modificable. Pero, al tiempo, la CEDAW abre el campo para la reivindicación de derechos y la vía jurídico/legal (otro aparato profundamente rígido y patriarcal) como mecanismo básico para acceder a ellos. La pregunta es si ello basta para modificar la cultura, la subjetividad, como lo propone la Convención.

Ideas como las de desarrollo y adelanto de la mujer "para el ejercicio y el goce de los derechos humanos y las libertades fundamentales en igualdad de condiciones con el hombre", como reza en el artículo 3 de la CEDAW, empiezan a "colonizar" los espacios que antes ocupaba un discurso, en algunos casos de inspiración marxista y en otros inspirado en los grupos de autoayuda que dominaron buena parte de la década de los $70 \mathrm{y}$ que demandaban desde entonces la libre maternidad y el aborto.

Progresivamente ese discurso va siendo fortalecido por los aportes de las mismas feministas del continente que han entrado en relación con sus afines del Norte (Estado Unidos y Europa), o han estudiado en aquellos países. Mujeres feministas expertas en planeación e investigadoras, ingresan a los organismos del establishment del desarrollo, a las oficinas de gobierno y a las Organizaciones no gubernamentales, incorporando las categorías de análisis y en general el discurso que se va constituyendo como parte del proceso de institucionalización y "visibilización" de las mujeres como actores sociales y políticos.

Categorías como mujer y desarrollo, género, género y desarrollo, empoderamiento, 
circulan de la academia norteamericana a la latinoamericana, y de esta a las ONG, a los Estados, a los medios de comunicación hasta abandonar la "ajenidad" que en un principio pudieran representar, para pasar de categorías analíticas y políticas a conceptos técnicos -es decir "neutros"- y finalmente a convertirse en términos del dominio común y cotidiano, desprovistos de su sentido inicial.

La declaración del Decenio de las Naciones Unidas para la Mujer: Igualdad, Desarrollo y Paz, constituye así uno, si no el más importante, de los factores en el proceso de una nueva visibilidad de la población femenina, en principio la más vulnerable: campesinas, pobres urbanas, indígenas, afrodescendientes, desplazadas por la violencia y la guerra interna, en el caso colombiano Fue posible entonces promover la investigación, canalizar fondos de la cooperación internacional y de los organismos del desarrollo, así como crear redes de trabajo, lazos de amistad e interacción académica y técnica entre feministas del Norte y del Sur. La divulgación de conocimiento feminista sobre las mujeres -de las del Sur por las del Norte en principio y luego de las del Sur sobre sí mismascirculó en publicaciones diversas.

Todo este clima internacional favoreció la formulación de políticas públicas "con perspectiva de género", por los gobiernos, particularmente a partir de finales de la década de los años 80, con la intención de que las metas de productividad no subordinen los procesos de "empoderamiento" de las mujeres y las diferencias biológicas no constituyan factor de subordinación (Escobar 2000:346-355).

Es en ese reordenamiento de las visibilidades, de los discursos sobre las mujeres que las configuraciones del poder (patriarcal) incorporan las diferencias. Subsiste la pregunta por la capacidad de estas transformaciones de penetrar, erosionar, los cimientos mismos del sistema, en la cultura y en las subjetividades femeninas y masculinas que por siglos hemos construido.

Como lo ha expuesto Foucault, el discurso no es la expresión del pensamiento, es una práctica, con condiciones, reglas y transformaciones históricas. Luego, analizar 'la mujer' como discurso es mostrar que agregar una frase a una serie de frases preexistentes es ejecutar un gesto costoso y complicado. Ese gesto costoso y complicado es el que produce el "género" de la mirada; la visibilización de las mujeres mediante este proceso de clasificación en categorías, es un efecto de poder que transforma a los individuos en sujetos, sujeto en su doble sentido, el de atado a su propia identidad y el de sometido a otros a través del control y la dependencia (Foucault 1988:7). Pero también en una doble operación: la de hacer visible, hablar de ella -y en este sentido hacerla objeto de intervención y de políticas públicas- y ocultar, silenciar sus propias vidas, su existencia. Lo que no cambia en esta operación es la naturaleza del régimen de representaciones que las produce, la naturaleza patriarcal de éste. 


\section{La agenda global para las mujeres en América Latina en los años 80}

Aunque no es fácil hacer cortes temporales en el proceso de construcción del campo discursivo sobre las mujeres, es preciso hacer un esfuerzo para delinear algunos de los elementos propios del contexto latinoamericano con el cual interactúa y se reconstruye, la agenda global.

Los años 80 son los de "la década perdida", en la que la pobreza, la crisis de la deuda externa y a pesar de las políticas para el desarrollo en América Latina, se profundizó la brecha entre ricos y pobres. Es también la década de transición del modelo de Estado de Bienestar y del agotamiento del proyecto socialista.

La promoción de la industrialización en el Tercer Mundo mediante plataformas de exportación y zonas de libre comercio ocurrió al mismo tiempo con los llamados de las organizaciones internacionales a "integrar a las mujeres al desarrollo". Sin embargo, la inclusión de la mujer como estrategia de desarrollo en ese momento, se apoya en y refuerza las prácticas y creencias sexistas y racistas existentes (Escobar 200:324-326). ${ }^{14}$ Esto es aplicable tanto a las mujeres del campo como a las de las fábricas pues, pese a que acceden a nuevas fuentes de ingreso, ello se traduce en un agravamiento en las condiciones de vida: mayor explotación, doble jornada, en especial para los sectores más pobres, urbanos y rurales. Este fue el efecto "feminización de la pobreza", ${ }^{15}$ a partir de las estrategias de "integración de las mujeres al desarrollo".

En 1980 se celebra la II Conferencia Mundial sobre la Mujer, en Copenhague, donde se aprueba el programa de acción para la segunda mitad del Decenio de la Mujer el cual enfatiza en las condiciones de empleo, salud y educación de las mujeres. A partir de este año las mujeres del continente promueven el desarrollo de Encuentros Feministas Latinoamericanos y del Caribe. El primero se realiza en Bogotá en 1981 y a partir de esta fecha, cada dos años han tenido lugar en distintos países latinoamericanos, sucesivos encuentros hasta la fecha. El X Encuentro tuvo lugar en Sao Paulo, Brasil, del 10 - 12 de octubre de 2005.

En 1985, en Nairobi, en la III Conferencia Mundial sobre la Mujer, se evalúa el Decenio y se aprueba por consenso el documento "Las Estrategias de Nairobi", orientado hacia el futuro y para el adelanto de las mujeres por los próximos 15 años (hasta el 2000). ${ }^{16}$ Este documento, preparado por la Comisión de la Condición Jurídica de la Mujer, del

\footnotetext{
${ }^{14}$ Sólo hasta este año (1980) la CEDAW pasa a la ratificación de los Estados

$15{ }^{15}$ No quiero desconocer la importancia del debate suscitado entonces sobre el tipo o la visión del desarrollo que se esperaba, sin embargo no es el objetivo en este caso. Sobre la discusión desde las académicas feministas, véase León (1996) en el que expone los distintos enfoques y su incorporación a los programas y/o proyectos específicos para la mujer en América Latina.

${ }^{16}$ www.isis.cl/temas/conf/beijing.htm
} 
Consejo Económico y Social de la ONU, además de ser considerado como otro de los logros importantes del decenio, es valorado por expertas en derecho internacional como una "interpretación auténtica" de las disposiciones de la Convención, en el sentido de que hay en ambos documentos un criterio común en cuanto a su significado (Plata y Yanuzova 1988: 27).

Es en este escenario de producción e institucionalización global de discursos sobre la mujer en el periodo 1975-1985, que el proyecto moderno de "progreso", traducido ahora en estrategias de "desarrollo", es propuesto como norte para el Tercer Mundo, especialmente para el sector rural, donde las condiciones de vida de las mujeres limitan sus posibilidades de "vincularse al desarrollo". Una de las tantas discusiones posibles alrededor del tan deseado desarrollo es la que argumenta que, formulado como el deber ser y la utopía de la modernidad, desconoce las diferencias y particularidades de los distintos pueblos que pretende homogenizar bajo la consideración de su "pobreza". El desarrollo, concebido como sistema de intervención técnica susceptible de aplicación más o menos universal, no toma en consideración la cultura local, la que implícitamente pasa a ser parte del problema, del obstáculo para el desarrollo y, por tanto, para el logro de la modernidad (Escobar 2000: 94).

La aludida estrategia para vincular la mujer al desarrollo relaciona inicialmente las dos categorías objetivo de la misma. Así, el término MYD -Mujer y Desarrollo- es acuñado por la sede de Washington de la Society for International Development que influye en la reorientación de la US AID (Agencia Interamericana para el Desarrollo), en 1973. Las actividades de MYD se incrementan dentro del sistema de Naciones Unidas desde comienzos de los setenta. Con la Década de las Naciones Unidas para la Mujer, se inicia el declive y con la Conferencia de Nairobi, su final (1985); el discurso sobre mujeres y desarrollo ponía énfasis en la contribución que las mujeres harían al logro de las metas generales del desarrollo.

Los debates y análisis de las académicas feministas sobre estas estrategias para el desarrollo como intervención planificada, profundizan en el asunto y además de la fórmula MYD, diferencian entre ésta y la de "Mujer en el Desarrollo" (MED) y la de "Género en el Desarrollo" (GED), ambas con una orientación general desde la mujer hacia el desarrollo, modificación introducida a partir de las críticas formuladas por las asesoras y académicas al planteamiento anterior (MYD) que se concebía en sentido contrario. Es importante subrayar que en GED y MYD hay un abandono de las formas más tradicionales de concebir a la mujer (como reproductora de la subordinación y de la fuerza de trabajo) y su aporte al desarrollo; sin embargo, como señala (León 1996:190), estrategias y enfoques se superponen indistintamente, sobre todo en los proyectos con enfoques de bienestar, antipobreza, equidad o productividad.

Lo significativo e importante de subrayar es que todos estos enfoques, unos más que otros, quedan atrapados en el modelo de progreso del proyecto de la modernidad que, como 
he señalado, concibe a la cultura local como su principal obstáculo.

La noción de género es introducida por las feministas académicas (Gayle 1975) ${ }^{17}$ norteamericanas como categoría analítico-política y es reintroducida en los organismos internacionales, especialmente en los de cooperación, como concepto técnico, es decir, supuestamente neutro, a finales de los años 80 e inicios de los 90, época en que llega con fuerza a América Latina; género, al igual que MYD, fue apropiado por el aparato discursivo de los organismos internacionales (económicos y políticos) del establishment del desarrollo.

De esta manera, iniciados los 90, la mayoría si no la totalidad de las agencias de cooperación empiezan a exigir la inclusión de la variable género como condición para obtener recursos para proyectos en América Latina. Desde posiciones de influencia en las decisiones, muchas feministas de Europa y Norteamérica, iniciaron una campaña internacional por la inclusión de la categoría género en el sistema de Naciones Unidas y en las agencias de cooperación para el desarrollo (Barrig y Wehkamp 1994).

\section{El fin de siglo: La globalización neoliberal y la agenda}

Como he señalado antes, si bien los procesos de articulación y complejización de instituciones, teoría, conceptos, estrategias y prácticas desde las cuales se hacen visibles las mujeres y sus demandas son fluidos en estos tiempos, los contextos en que tienen lugar presentan cambios que plantean nuevos desafíos al proyecto del feminismo latinoamericano.

Así las cosas, finalizando la década de los años ochenta e iniciando los noventa, toma fuerza en el mundo occidental el proyecto neoliberal con su estrategia de globalización económica y tecnológica. La complejidad de la economía global actual tiene que ver con ciertas dislocaciones fundamentales entre la economía, la cultura y la política que sólo recientemente se han empezado a teorizar (Appadurai 2001:46).

Tales cambios se han producido en el propio modo de producción capitalista en su estadio avanzado: transformaciones en las estructuras de producción y reproducción que ya

\footnotetext{
${ }^{17}$ Gayle Rubin introdujo la categoría sexo-género. Scott Joan sostiene en una primera proposición, que "el género es un elemento constitutivo de las relaciones sociales basadas en las diferencias que distinguen los sexos"; en la segunda, dice que "el género es una forma primaria de relaciones significantes de poder". El género tiene en la definición de Scott, cuatro aspectos o dimensiones en que es particularmente útil y que están relacionados entre sí: 1. lo simbólico, 2. la dimensión conceptual normativa, 3. nociones políticas, instituciones y organizaciones sociales y 4. la dimensión subjetiva del género. Cfr. Scott, (1990: 44-49). Usa el género como una categoría analítica. Algunas feministas han cuestionado la introducción del sistema de género, que aunque representa un instrumento de análisis de significativa importancia práctica a la hora de incluir el criterio diferencial para definir políticas sociales, por ejemplo, tiene la carga de su origen en el también cuestionado sistema de análisis binario tradicional occidental, entre otras críticas.
} 
no se sustentan en el capital industrial y la fuerza de trabajo típica de etapas previas (sin que ello signifique que han desaparecido), han dado lugar a nuevas formas de producción "postindustriales" en las que ya no sólo la naturaleza es valor de cambio sino también la información y la tecnología - medio y fin en la producción hoy-, el entretenimiento, objetos de consumo diario, moda y hasta la vida producida y transformada genéticamente, son hoy valores de cambio.

Los intensos procesos de globalización (económicos, tecnológicos, culturales) que caracterizan estas transformaciones, han ido desdibujando las formas tradicionales de organización en estados nacionales (sin que desaparezcan, pues funcionan adaptándose a las nuevas exigencias del mercado mundial), situando en el centro del orden mundial, instituciones y organizaciones que hoy hacen la gestión que antes desarrollaban las burguesías nacionales, a la vez que regulan y controlan la reproducción del capital, así como la producción y reproducción de imágenes y símbolos (Castro-Gómez 2003:67).

Tales transformaciones dominadas por la "lógica cultural del capitalismo avanzado" (Jameson 1995), afectan a las formaciones sociales contemporáneas, sus formas de vida, producción, interacción, reproducción, socialización y, por tanto, sus maneras de percibir el mundo, el tiempo y el espacio, el futuro, las identidades, las nacionalidades, el sí mismo, el nosotros y a los otros y otras. Sin embargo, los viejos problemas subsisten, acentuados hoy por el predominio de las transformaciones aludidas.

En América Latina la década de los años noventa ha sido definida por los "procesos de democratización" ocurridos en los países que experimentaron regímenes autoritarios durante buena parte del siglo XX; en Colombia, con una historia reciente de regímenes democráticos formales, pero con la pervivencia y agudización de la violencia política (confrontación armada de grupos guerrilleros, paramilitares y delincuencia organizada a partir del tráfico de drogas), ésta se ha intensificado en las últimas décadas del siglo XX, con efectos de degradación en la confrontación armada.

Núcleo fundamental de esta fase del capitalismo avanzado luego del fracaso del proyecto socialista y del desmonte del Estado de Bienestar, es la visión neoliberal de la economía y la política, sustentada en la filosofía liberal del individualismo posesivo (MacPherson 1970), liderada por la nueva derecha neoconservadora (Hayek 1978) que se hace hegemónica en el planeta.

En los Estados nacionales se dan un conjunto de desplazamientos en sus funciones y atribuciones con la finalidad de servir a los objetivos del capital transnacional. Frente a la idea generalizada de "menos Estado y más mercado", los que se producen -con diversas variantes según los Estados de que se trate- son procesos de descentramiento/reconcentración de funciones tradicionalmente circunscritas a un territorio, su ordenamiento jurídico y el control de la fuerza, que pueden dar lugar a nuevos ordenamientos regionales o transnacionales, sin olvidar lo que los Estados nacionales, sobre 
todo pequeños y/o pobres puedan perder en términos de soberanía.

Estas dislocaciones en los Estados, producto de una política económica centrada en el mercado, generan cambios fundamentales en el sistema interestatal: los Estados hegemónicos y sus instituciones internacionales controlan la autonomía política y la soberanía de los países económica y políticamente débiles, mermando su capacidad de resistencia y negociación.

¿Qué pasa en este clima con los movimientos sociales, con las mujeres organizadas y con la cooperación internacional? O, más radicalmente, como lo plantea Francesca Gargallo (2004): ${ }^{18}$ “Por qué, en la década de 1990, el feminismo latinoamericano dejó de buscar en sus propias prácticas, en su experimentación y en la historia de sus reflexiones, los sustentos teóricos de su política? ¿Por qué aceptó acríticamente la categoría gendergénero para explicarse y la participación en "políticas públicas" como solución a la crisis del movimiento, según lo exigía la cooperación internacional?" (Gargallo 2004)

Uno de los efectos del desplazamiento en los Estados, dentro del nuevo orden neoliberal es el fortalecimiento de instituciones de la "sociedad civil" que actúan como puente o mediadoras entre los Estados y sus políticas y los "beneficiarios". Aunque las hay de muy diverso tipo, para la finalidad del período que nos interesa, tienen particular importancia las denominadas Organizaciones no gubernamentales de desarrollo, ONGD, que canalizan los recursos de la Cooperación Internacional y las que se constituyen localmente para hacer lo propio para que esos recursos permitan el trabajo "de base" (Fontela y Belloti 1999). Este aparato burocrático-administrativo, generalmente con cuadros profesionales muy calificados, terminaron confundiéndose con la "sociedad civil" $\mathrm{y}$, los propios movimientos sociales, invadidos por el fenómeno de la ONGización, abandonaron su sentido crítico, reivindicativo, demandante y "privatizaron" el movimiento.

En esta misma lógica, a lo largo de la década de los años noventa, Naciones Unidas abren un espacio para la construcción (¿continuidad?) de una Agenda Global, a través de las Cumbres y Conferencias Mundiales sobre temas de política democrática, agenda en la cual toman parte activa en su definición, organizaciones feministas regionales, locales y continentales, ahora profesionalizadas y constituidas en ONG (Álvarez 2001:362-367). Dos aspectos subrayo de los encuentros de organizaciones feministas latinoamericanas, y de éstas con las instancias de Naciones Unidas, en términos de definición de agenda y estrategias de trabajo:

Por una parte, estos eventos llamaron la atención sobre la difundida actividad feminista en los países de Latinoamérica, lo cual indica la configuración de una cierta

\footnotetext{
${ }^{18}$ Una de las cosas que llaman la atención cuando analizamos los movimientos sociales, y en este caso los de mujeres/feministas, es el abandono casi absoluto de crítica y por supuesto de autocrítica en la literatura de la última década.
} 
identidad política latinoamericana. Programas, proyectos, discursos, debates, elaboraciones conceptuales y de categorías originados en el Norte, fueron a su vez absorbidos, apropiados, reconfigurados, aclimatados $\mathbf{y}$ resignificados por muchas otras organizaciones de la "sociedad civil" -no sólo de mujeres-, de la sociedad política y del Estado. Y es importante subrayar lo que aporta Appadurai (2001:46) en este sentido: "aunque muchas fuerzas culturales provenientes de las metrópolis logran imponerse, ellas son pronto aclimatadas y nacionalizadas de diversas maneras: esto vale tanto para los estilos musicales, como para la ciencia, el terrorismo, los espectáculos y las constituciones".

Es decir, como lo he planteado con anterioridad, no es una operación en un solo sentido, pues los movimientos sociales no son sujetos pasivos de las pretensiones de imposición y control de éstas y otras fuerzas; además, sus objetivos e intereses estratégicos, se concretan en escenarios complejos y problemáticos, en interacción con ellos, con los Estados, con otras organizaciones y movimientos.

El segundo aspecto, junto con lo anterior, tiene que ver con la creciente profesionalización de los movimientos feministas y la constitución de Organizaciones No Gubernamentales (ONG) y lo que es tal vez más importante, la creciente creación de redes entre los distintos lugares de actividad política feminista. Múltiples y disímiles grupos y organizaciones forman hoy parte de ese proceso de constitución de la sociedad red (Castell 1997).

En esta década la agenda global de Naciones Unidas para "la mujer" va a desplegar nuevos items enmarcados en la no discriminación, es decir en el derecho a la igualdad y la libertad: el tema de la violencia de género y contra la infancia, es incorporado al discurso sobre la mujer y a la legislación en cada país. Los derechos sexuales y reproductivos son el ámbito de desarrollo del trabajo de las organizaciones y de la cooperación internacional, que promueve una progresiva desagregación de los derechos de la mujer (¿efecto de poder?). Así mismo, junto con las ideas de ciudadanía "plena”, se avanza en la promoción de la participación política de las mujeres, no sólo en los procesos electorales, sino también buscando insertarse en posiciones de poder y decisión y en el ejercicio del lobby (propio del lenguaje del inicio de la década) y el advocacy (instalado en el lenguaje hacia el 2000).

Las sucesivas Conferencias refuerzan/amplían/profundizan/especializan la agenda inaugurada con la CEDAW, conforme a los problemas más sentidos en la región:

La Conferencia Mundial sobre Derechos Humanos, Viena, 1993, ${ }^{19}$ reconoce que la violencia contra las mujeres y las niñas constituye una grave violación de los derechos humanos. La Conferencia Internacional sobre Población y Desarrollo, El Cairo, 1994,

\footnotetext{
${ }^{19}$ www.isis.cl/temas/conf/beijing.htm
} 
reconoce que los derechos reproductivos son derechos humanos y que la violencia de género es un obstáculo para la salud reproductiva y sexual de las mujeres, la educación y el desarrollo. La Cumbre Mundial sobre Desarrollo Social, Copenhague, 1995, entre otros compromisos se propone reconocer y aumentar la participación y función directiva de la mujer en la vida política, civil, económica, social y cultural. También de este año es la Convención Interamericana para Prevenir, Sancionar y Erradicar la Violencia contra la Mujer, Convención de Belém do Pará.

La IV Conferencia Mundial sobre la Mujer, realizada en Beijing, también en este año, aprueba la Declaración de Beijing y una Plataforma de Acción. La Declaración compromete a los gobiernos a impulsar, antes del término del siglo XX, las estrategias acordadas en Nairobi en 1985 y a movilizar recursos para la realización de la plataforma. La Plataforma de Acción de Beijing es el documento más completo producido por una conferencia de Naciones Unidas en relación con los derechos de las mujeres, ya que incorpora lo logrado en conferencias y tratados anteriores. ${ }^{20}$

Fue la Conferencia de Beijing y, por supuesto, el financiamiento de Naciones Unidas a los nodos regionales, lo que a su vez favoreció una ampliación y difusión en los países latinoamericanos, del proyecto, los discursos y los programas de las mujeres autodefinidas como feministas, pero también de otras, que no se sentían tales.

"El proceso latinoamericano de Beijing parecía señalar una nueva multiplicación vertiginosa de espacios y lugares en los cuales las mujeres que se reafirman como feministas actúan hoy en día así como una nueva configuración de las identidades feministas (...) las fronteras que separaban las prácticas feministas de las no feministas se habían hecho aún más inestables. Los movimientos feministas de la región se hicieron menos homogéneos, menos unificados y más diversos en sus discursos y prácticas durante la última década". (Álvarez 2001:353).

Así mismo, como lo registra Sonia Álvarez, los procesos suscitados por Beijing, pusieron de presente la presencia de grupos renovados de mujeres, que no sólo se resistían a los "viejos" cánones del feminismo de la segunda ola, así como a sus escenarios y espacios convencionales, sino que, además, reivindicaban un conjunto de diferencias existentes siempre, pero invisibles en el discurso hegemónico de las feministas del Norte. Se hizo notar el feminismo negro, el lésbico, el popular, el ecofeminismo, el cristiano, de grupos con una trayectoria personal y política que ya no transitaba necesariamente por los caminos y los problemas que tuvieron que afrontar "las históricas". Sus discursos subrayaban las maneras como raza/etnia, clase, orientaciones sexuales, entre otras, son constitutivas de las identidades de las mujeres.

${ }^{20}$ Ídem. 
En relación con los estados nacionales, durante la década, dentro y junto con los programas de ajuste estructural, los movimientos de mujeres lograron negociar, tal vez por vez primera, y con el respaldo de Naciones Unidas, políticas nacionales en toda la región que dieron lugar a la creación de programas, agencias, ministerios, así como legislación incluso de nivel constitucional, como fue el caso de Colombia, que incorporó normas ${ }^{21}$ en torno a la igualdad entre hombres y mujeres y mecanismo expeditos de protección de los derechos, especialmente de mujeres y niños/niñas, todos ellos asuntos planteados ya desde la CEDAW una década atrás.

"El propio proceso de la ONU ha otorgado una legitimidad nueva o renovada a las exigencias de justicia de género feminista domésticas y regionales. Durante la última década, el lenguaje de numerosos documentos oficiales de la ONU, de los gobiernos nacionales (...) abundan en planteamientos feministas de vieja data que van desde exigencias de políticas educativas no sexistas hasta participación más equitativa en la vida pública y familiar, y los derechos reproductivos" (Álvarez 2001:359).

Lo que interesa destacar aquí no es sólo el proceso de constitución de redes de mujeres que cruzan las fronteras nacionales, sino lo que ello hace con el discurso (proyectos, propuestas, discursos específicos, legislaciones, conceptos, construcciones simbólicas e imaginarios, estrategias, prácticas, formas de organización...) cada vez más complejo y diversificado y lo que ello a su vez produce en la construcción de ese sujeto femenino, individual y colectivo. Lo que ha ocurrido es que el discurso feminista (aunque luego pierda este sentido) se ha descentrado, ${ }^{22}$ ha abandonado los exclusivos espacios del debate académico/político y ha sido incorporado (también cooptado, apropiado...) por los gobiernos nacionales, por los medios de comunicación, por las agencias de cooperación internacionales sin olvidar la mediación de los programas de la ONU, la cual ha contribuido a que todo esto pase.

Al respecto, está por hacerse una evaluación de este efecto descentramiento, que en un sentido puede ser positivo al romper el aislamiento al tiempo que el discurso circula y se difunde; sin embargo, está el lado negativo de la "despolitización" del mismo. Adicionalmente hay que tener en cuenta un fenómeno de frecuente ocurrencia: el de los

\footnotetext{
${ }^{21}$ Ver Constitución de Colombia de 1991, entre otros el Título 2, arts. 13, 42-44; y el art. 86 que consagra la "acción de tutela" como un mecanismo expedito para la protección de los derechos.

${ }^{22}$ La noción de descentramiento de las prácticas feministas latinoamericanas contemporáneas está expuesta por Sonia Álvarez (2001:354); subraya ella cómo las feministas latinoamericanas, hacia mediados de los años noventa, llevan sus discursos y prácticas de transformación a una variedad de escenarios socioculturales y políticos. Siguiendo esta perspectiva de análisis para el movimiento en Colombia, en el inicio del siglo XXI, es posible no sólo verificar la ocurrencia del mismo fenómeno de descentramiento, sino la apropiación del discurso o fragmentos de éste, por parte de la sociedad civil y el Estado. La pregunta que subsiste es acerca de qué ocurre con el discurso y las prácticas feministas cuando se descentran. Aunque vuelvo más adelante sobre este efecto descentramiento en el movimiento, es muy probable que para dar cuenta de ello sea necesario indagar en esos otros espacios donde el discurso y las prácticas feministas han llegado.
} 
efectos perversos o no buscados de la acción humana, individual o colectiva.

Sin embargo, se puede constatar que la experiencia de ampliación del discurso no es homogénea, no ha favorecido con igual intensidad a todos los grupos y países e, indudablemente, hay en juego no sólo múltiples intereses, sino también estrategias que controlan con más eficacia ciertos grupos entrenados en las artes del lobby y de las relaciones internacionales, así como en la gestión de recursos y proyectos. Pero es parte de la dinámica que las mismas mujeres han construido y en la que participan o no, según sus posibilidades. Es, así mismo, expresión de una lucha cultural, de una confrontación semiótica y política, por el control de las significaciones, no sólo de los recursos y los medios, para institucionalizar una determinada perspectiva o visión del ser mujer en la cultura.

Así, lo que esta dinámica muestra son procesos muy complejos en los que intervienen actores de diverso tipo y capacidad de negociación/decisión, lo que implica la necesaria concurrencia de relaciones de poder y regímenes de representaciones sociales que juegan papeles claves, no siempre desde el lugar de las élites, también desde el lugar de las resistencias, así como de múltiples e impredecibles combinaciones que, a la vez que constituyen, son constituidas en los propios procesos de construcción de los actores sociales colectivos.

Por otro lado, un factor que atraviesa estos discursos y los hace mucho más complejos, a la vez que atenúa, diluye o desaparece las preocupaciones iniciales y propias del movimiento de mujeres y de las organizaciones que trabajan en este sentido frente a la cultura patriarcal, es el asunto de la guerra en Colombia y las distintas fuerzas involucradas en el conflicto. Esto es, no sólo bandos armados y confrontados con el Estado desde dentro, sino también fuerzas que de diferentes maneras influyen desde fuera, del exterior -vía cooperación financiera o humanitaria, entre otras-. Con ocasión del conflicto colombiano, la presencia en territorio colombiano de agencias, oficinas, representantes, del sistema Naciones Unidas, pero también de otros organismos europeos, entidades particulares, iglesias, con recursos y ayuda humanitaria para la población afectada por la guerra, la pobreza y el desplazamiento forzado, constituyen una importante burocracia técnica, de expertas y expertos, asesores, altos comisionados, que orientan permanentemente la agenda de las organizaciones, no sólo de mujeres.

No es la intención desentrañar la gran conspiración, ni buscar culpables o responsables; de lo que se trata, más bien, es de observar cómo los discursos sobre la mujer constituyen una estrategia de investigación alternativa para dar cuenta de la dinámica de la acción colectiva de estos movimientos en el periodo señalado. Adicionalmente, creo que el ejercicio crítico focaliza y enfatiza aspectos que de otra manera pueden pasar inadvertidos o volverse tan familiares y cotidianos que asumamos sencillamente que no hay otra manera de ser y de hacer. 
En este orden de ideas, contra toda reiterada queja del movimiento acerca de la necesidad y dificultad de construir una agenda conjunta, lo que este recorrido muestra es que hemos ido construyendo una a lo largo de 30 años, vigente hoy.

Es importante también subrayar en el proceso de construcción/institucionalización del campo discursivo, que la CEDAW inscribe una matriz que reinaugura el discurso de la no discriminación, que traslada de un contexto radical y crítico a otro sustentado en los principios de la democracia liberal, orientado a fortalecer el proyecto de la modernidad cada vez más globalizado, con el cual es, sin embargo, incompatible la existencia real que llevan la mayoría de las mujeres en el mundo.

En el proceso de implementación de la CEDAW se opera una desagregación sucesiva de los derechos por razones prácticas y de condiciones particulares de grupos de mujeres, desagregación que se apuntala con las sucesivas conferencias y convenciones que enfatizan en unos u otros derechos.

Los derechos económicos y sociales toman posición relevante, por razones de sobrevivencia de los grupos, así como el ejercicio de derechos políticos; sin embargo otros, los sexuales y reproductivos, máxima bandera y corazón de las reivindicaciones feministas de los 70 sigue siendo el talón de Aquiles de la CEDAW y del proyecto feminista de transformación cultural.

Lo que ha ocurrido en los últimos 30 años ha sido la incorporación progresiva y sostenida del discurso y el proyecto feminista (su matriz fundamental) en el de la Democracia como único posible en el contexto de las sociedades occidentalizadas del fin de siglo. Los más incómodos siguen siendo los Derechos Sexuales y Reproductivos, incómodos sí, para culturas intolerantes y fundamentalistas como las nuestras, pero, en verdad, nada revolucionarios, apenas liberales. Sí, demandar el reconocimiento y la inclusión es legítimo como bandera de lucha, pero ¿es suficiente con la formulación como derecho y la inclusión en la legislación nacional e internacional para cambiar la cultura, la mentalidad, la discriminación en nuestras maneras de ver y valorar a las otras y los otros distintos del ideal moderno masculino, cristiano, blanco? 


\section{Bibliografía}

Álvarez Sonia (2001), "Los feminismos latinoamericanos se globalizan": tendencias de los 90 y retos para el nuevo milenio", en, Escobar et al, Política cultural \& Cultura política, Taurus - Instituto Colombiano de Antropología e Historia, Bogotá.

Appadurai, Arjun (2001), La modernidad desbordada. Dimensiones culturales de la globalización, FCE, Buenos Aires.

Barrig, Maruja, et al. (1994), Sin morir en el intento. Experiencias de planificación de género en el desarrollo, Novib - Red Entre Mujeres, Lima.

Castells, Manuel (1997), La Era de la información. El poder de la identidad (Vol. 2), Alianza Editorial, Madrid.

Castro-Gómez, Santiago (2003), "Apogeo y decadencia de la teoría tradicional. Una visión desde los intersticios", en Estudios Culturales Latinoamericanos. Retos desde y sobre la región andina, C. Walsh (ed.), UASB/Abya Yala, Quito.

Escobar, Arturo (2000), La invención del Tercer Mundo, construcción y deconstrucción del desarrollo, Editorial Norma, Bogotá.

Fontenla, Marta y Belloti, Magui (1999), "ONG, financiamiento y feminismo", en Hojas de Warmi $N^{o} 10$, Barcelona.

Gargallo, Francesca (2004), Las ideas feministas latinoamericanas, Ediciones Desde Abajo, Bogotá.

Guzmán, Laura (1996), "IV Conferencia Mundial sobre la Mujer: Interrogantes, nudos, y desafíos sobre el adelanto de las mujeres en un contexto de cambio", en Estudios Básicos de Derechos Humanos IV, Instituto Interamericano de Derechos Humanos, San José de Costa Rica.

Hayek, Friederich (1978), Los fundamentos de la libertad, Unión Editorial, Madrid.

Jameson, Fredric (1995), El posmodernismo o la lógica cultural del capitalismo tardío, Paidós, Barcelona.

León, Magdalena (1996), "Mujer, género y desarrollo. Concepciones, instituciones y debates en América Latina", en Estudios Básicos de Derechos Humanos IV, Instituto Interamericano de Derechos Humanos, San José de Costa Rica.

Ídem (1993), “Avances y limitaciones de la relación Estado Mujer en América Latina”, en Memorias de la IX Jornada de Investigación Interdisciplinaria sobre la Mujer, Instituto Universitario de Estudios de la Mujer de la Universidad Autónoma de Madrid.

Ídem (1993a), "El género en la política pública en América Latina: neutralidad y distensión", en Análisis Político $N^{o} 20$, septiembre-diciembre.

MacPherson, C. B. (1970), La teoría política del individualismo posesivo. De Hobbes a Locke, Edit. Fontanella, Barcelona.

Mignolo, Walter (2003, Historias locales/Diseños globales. Colonialidad, Conocimiento subalterno y pensamiento fronterizo, Akal, Madrid.

Plata, María Isabel y Yanuzova, María (comp.) (1988), Los Derechos Humanos y la Convención sobre la eliminación de todas las formas de discriminación contra la mujer - 1979, Profamilia/ Fundación Ford, Bogotá.

Scott, Joan (1990), "El género una categoría útil para el análisis histórico", en Amelang, James y Nash, Mary (edits.) Historia y género, Alfons el Magnanim, Valencia, España.

Roig, Monserrat, (1985), El feminismo, Salvat Editores, Barcelona. 
REVISTA POLIS

VOL. $7 \mathrm{~N}^{0} 20,2008$

LA AGENDA GLOBAL DE LAS NACIONES UNIDAS PARA "LA MUJER", 261-283

C EDITORIAL DE LA UNIVERSIDAD BOLIVARIANA DE CHILE, 2008

Valdés, Teresa (2000, De lo social a lo político. La acción de las mujeres latinoamericanas, LOM Ediciones, Santiago de Chile.

Walsh, Catherine (2002), "Las geopolíticas de conocimiento y la colonialidad del poder", en Indisciplinar las ciencias sociales, C. Walsh, F. Schiwy y S. Castro-Gómez (eds), Abya-Yala, Quito..

www.isis.cl/temas/conf/beijing.htm 